\title{
EDITORIAL
}

\section{CMAJ and antiracism}

\author{
Kirsten Patrick MB BCh MSc
}

Cite as: CMAJ 2021 March 29;193:E453-4. doi: 10.1503/cmaj.210494

n

n early 2021, CMAJ published articles calling for dismantling racism in Canadian health care and medical academia. ${ }^{1-3}$ We've had encouraging feedback on these articles. I was disturbed, however, by some emails and voice messages in which readers expressed their outrage that CMAJ would provide a platform for the notion that racism exists at all, either in Canada or in the medical profession. One person stated flatly, "There is no racism in Medicine." Another, while allowing that racism happens occasionally on the interpersonal level, opined that structural racism doesn't exist in Canada.

I am writing today to state categorically CMAJ's position on the matter, which is that systemic racism exists in Canadian society and within its health care systems. My purpose here is not to debate the existence of racism in Canada. Ample evidence and testimony support its existence. I invite readers to acquaint themselves with it. As CMAJ is part of the system that produces medical knowledge, it is and has been part of the problem. It is essential that we recognize how and take action to be part of the solution.

Medical journals have power. Journals, and those who work for them, are among the gatekeepers of the information that guides policy-making and service provision in health systems. Journal editors have powerful platforms from which they can influence scientific inquiry and policy narratives. Therefore, the diversity of those who sit at the editorial decision-making table should reflect the diversity of health care stakeholders. Marginalized voices must be heard to effect change.

Scientific journals the world over responded to events in 2020 by publishing editorials, features and commentaries on the impact of racism, emphasizing their solidarity with an antiracism movement. Some have run special issues on racism in medicine. Yet critics have questioned their motives; for example, a scholar observed "some academic journals that have recently claimed to have a commitment to racial equity are publishing critical work only in the form of commentaries and op-eds, while theoretically grounded, empirical critical work does not get past their peer review process." 4

It is important to hear and reflect on such criticisms rather than be defensive. CMAJ has in recent years published much research highlighting health disparities for racialized groups compared with White people in Canada. Yet merely showing that
Black or Indigenous people in Canada have worse outcomes on certain measures of health is not the same as showing that racism causes these health inequities, nor does it address any underlying structural problems.

Scholars in the social sciences have generated evidence of the effects of racist policies for more than a century. ${ }^{5,6}$ Recent decades have seen medical research incorporate the interplay between social experience and health outcomes, and the extent to which some social determinants affect health status is now well understood. However, it is easier to measure and correlate income, housing status and education with health than it is to quantify the cumulative effects of a lifetime of social exclusion and oppression. As such, our understanding of the effects of racism on health (as opposed to correlations with race or ethnicity) is less well advanced. One barrier to answering relevant questions about the health effects of racism is inadequately granular data. Put simply, although we may ask people to check a "race" box, we seldom ask them to provide data on their experience of racism.

CMAJ cannot directly influence what research is funded and conducted in Canada, but it can provide a platform for those who would articulate what research is needed, which data must be collected, and which methods can be used to allow the proper study of racism in health care. We would welcome submissions of innovative research on interventions to reduce both racism in the health space and the effects of racism on health.

As interim editor-in-chief of CMAJ, I will work to further an antiracism agenda at the journal. In the short term, to alter the balance of power among those who make editorial decisions, I will seek to add an editor with expertise in critical race theory to CMAJ's editorial team, and add a member to the journal's existing Editorial Advisory Board who can advise knowledgeably on the development of antiracist policies. CMAJ's existing editorial team will receive unconscious bias training and regular education related to relevant developments in research methods. We will continue to commission and publish articles that critically address racism's impact on the health of people in Canada and seek to present real solutions.

To some readers this editorial will be long overdue. To those who have already pointed out structural racism at CMAJ and have patiently taken the time to educate me, I thank you. I expect readers of CMAJ to hold me accountable to these stated intentions. 


\section{References}

1. Dryden $\mathrm{O}$, Nnorom $\mathrm{O}$. Time to dismantle systemic anti-Black racism in medicine in Canada. CMAJ 2021;193:E55-7.

2. Datta G, Siddiqi A, Lofters A. Transforming race-based health research in Canada. CMAJ 2021;193:E99-100.

3. Sharda S. Dhara, Alam F. Not neutral: reimagining antiracism as a professional competence. CMAJ 2021;193:E101-2.

4. @Arrianna_Planey Planey AM. "I'm observing that some academic journals that have recently claimed to have a commitment to racial equity are only publishing critical work in the form of commentaries \& op-eds, while theoretically-grounded, empirical critical work does not get past their peer review process." Twitter 2021 Feb. 9. Available: https:// twitter.com/Arrianna_Planey/status/1359273820947939332 (accessed 2021 Feb. 9).

5. DuBois WEB. The Philadelphia Negro: a social study. Philadelphia: University of Pennsylvania Press; 1996. Available: www.jstor.org/stable/j.ctt3fhpfb (accessed 2021 Mar. 6).

6. Jones $\mathrm{CP}$, Truman $\mathrm{BI}$, Elam-Evans LD, et al. Using "socially assigned race" to probe white advantages in health status. Ethn Dis 2008;18:496-504.
Competing interests: See www.cmaj.ca/site/misc/cmaj_staff. xhtml.

Affiliations: Interim editor-in-chief, CMAJ

Content licence: This is an Open Access article distributed in accordance with the terms of the Creative Commons Attribution (CC BY-NC-ND 4.0) licence, which permits use, distribution and reproduction in any medium, provided that the original publication is properly cited, the use is noncommercial (i.e., research or educational use), and no modifications or adaptations are made. See: https://creativecommons.org/ licenses/by-nc-nd/4.0/

Correspondence to: CMAJ editor, editorial@cmaj.ca 